DOI: 10.1515/linpo-2015-0006

\title{
On focus marking and predication. Evidence from Polish with some notes on Hausa
}

\author{
Przemyslaw Tajsner \\ Faculty of English, Adam Mickiewicz University, Poznań \\ tprzemek@wa.amu.edu.pl
}

\begin{abstract}
Przemysław Tajsner. On focus marking and predication. Evidence from Polish with some notes on Hausa. The Poznań Society for the Advancement of Arts and Sciences, PL ISSN 0079-4740, pp. $113-138$

Purpose: The primary aim of the paper is to provide a new, derivational analysis of two types of Polish sentences with the occurrence of a particle to, which syntactically code focus and topic. These are: to-clefts (To Janek napisat list. 'It was Janek who wrote the letter'), and topic-to sentences (Janek to napisat list. 'As for Janek, he wrote the letter'). The secondary aim is to reflect on the relevance of the isomorphism of focus markers and non-verbal copulas in Polish with some reference to Hausa.

Method: The approach follows a minimalist method but departs from cartographic accounts with dedicated heads in sentence left-periphery. Instead, it postulates that focus and topic are interpretive byeffects of Specification Predication. In this, the paper extends and modifies Kiss's $(2006,2010)$ central idea that focusing is predication.

Result \& Conclusion: The account proves successful in explaining a few syntactic constraints, doing so in a simple, unitary fashion. Viewing focus as a derivative of predication is a step towards understanding the relation between narrow syntax and information structure.
\end{abstract}

Keywords: focus, predication, topic, derivation, cartography

\section{Introduction ${ }^{1}$}

The question of the links between information structure and narrow syntax has been a matter of a lively debate in recent years. One of the issues raised in this dispute is whether focus should have a status of legitimate syntactic category, or rather, it should remain a notion of the interpretive system only. The difference between these two stands is, basically, that under the former focus is a formal feature, active in a narrow syntactic derivation and linked to a dedicated functional head, while the latter regards focus as a way of interpreting a specific syntactic and phonological configuration at the C-I interface. The former approach has developed extensively as part of the cartographic view of the left periphery of sentence

${ }^{1}$ I would like to thank two anonymous reviewers for their insightful comments on an earlier version of this article. I take all responsibility for any remaining errors or inadequacies. 
structure, in which a dedicated Foc (or F) head (probe) attracts a phrase (goal) with a matching feature to its specifier position. The latter approach, although dispensing with a focus functional head, need not be anti-cartographic; a configuration interpreted as focus may involve a left-periphery position, without its special dedication to focus.

The complications for the formal characterization result from its heterogeneity: (i) focus can be in-situ or ex-situ, (ii) its interpretation is not uniform: it can be exhaustive, contrastive, or plainly informational, (iii) its scope may be narrow or wide, (iv) its identification may involve change of word order, lexical or morphological markers, or be accomplished by prosody alone. A diversity of interpretative effects associated with focus and its syntactic under-specification may be seen as two initial counter-arguments to a syntactic provenance of the phenomenon. The proposal advocated in the present paper goes in this direction; it will be argued that focus should be excluded from a range of syntactic primitives. Typical ex-situ focus configurations, such as clefts, should not be treated as specifically dedicated to focus, but rather as constructs representing a less specified syntactic type that Kiss (2006) calls specification predication.

The three main goals of the paper are: (i) to offer an extension of Kiss's (2006) view of focus as predication, (ii) to provide support and instantiation for such a view from Polish, and (iii) to reflect on some intriguing correlation in the grammar of focus and non-verbal copular sentences between Polish and Hausa. The organization of the paper is as follows. It starts from the presentation of some cross-linguistic data on lexical focus marking and points to an often observed isomorphism between focus markers and non-verbal copulas. Next, the grammars of two genetically unrelated languages, Polish and Hausa, will be compared with a view to showing similarities and differences in their handling of the phenomenon of focus. This will be followed by a brief exposition and the extension of the framework (Kiss 2006; 2010) in which focus is viewed as a form of predication. Next, the inadequacies of a classical cartographic approach to two types of Polish constructions with the occurrence of a focus particle to will be briefly discussed, and an alternative analysis, fitting the focus as predication proposal, will be presented. The discussion ends with the summary and conclusions.

\section{Data and premises}

\subsection{Focus markers}

One of the ways focus can be marked in sentences is through dedicated lexical markers. Such a strategy is fairly widespread across languages. For example, in Mandarin, the shi ... de marking is used for the formation of clefts:

$$
\begin{array}{llll}
\text { tamen } \frac{\text { shi }}{\text { zuotian daoda Xinzhu de }} & \text { (Mandarin) } \\
\text { they } & \text { be yesterday reach Xinzhu de } & \\
\text { 'It's yesterday that they arrived in Xinzhu.' } & \text { (Marie-Claude Paris 1998: 153) }
\end{array}
$$

(Mandarin)

In a Chadic language Kanuri a focus marking clitic má follows a focused constituent:

$$
\begin{array}{ll}
\text { Allì-má } & \text { lè-zo-nà } \\
\text { Ali-FOC } & \text { go-3S-PERF }
\end{array}
$$

'Ali, too, has gone.' 'Even Ali has gone.' 
In Tagalog there is an enclitic lang whose function is to mark exhaustive identification on the clause-initial constituent, as shown in (3):

$$
\begin{aligned}
& \text { Siya }=\text { lang ang }=\text { [na-tulog } \quad \text { sa=bahay]. [cleft }] \\
& \text { 3.SG.NOM=only NOM=AV:slept DAT=house } \\
& \text { 'Only HE slept in his house.' } \\
& \text { (lit. 'The one who slept in his house was only him.' })^{2}
\end{aligned}
$$

In Polish, cleft-sentences feature a clause-initial marker to, as shown in (4):

$$
\begin{array}{llll}
\text { To } & \begin{array}{l}
\text { Tomek } \\
\text { FM }
\end{array} \text { Tomek } & \text { started } & \text { fight }
\end{array}
$$

'It was Tomek who started the fight.'

A more restricted phenomenon cross-linguistically is the identity of a focus marker with a non-verbal copula used in copular clauses. Such an isomorphism has been reported, for example, for Sumerian (Huber 1999; Kiss 2006) or Mupu (Frajzyngier 1993; Green 2007). Interestingly, the identity of focus markers and non-verbal copulas can be observed in genetically unrelated languages, such as Hausa (Chadic) and Polish (Slavic). ${ }^{3}$ The relevant facts are given in (5) and (6) below:

$\begin{array}{llll}\text { gà mālàm } & \underline{n e} & n a & \text { mai dà littāfin } \\ \text { to teacher } & \text { FM.m } & \text { 1s.FOCPF } & \text { return PART book.DD }\end{array}$

'I returned the book to the teacher.'

(Hausa)

(Green 2007: 62)

$\begin{array}{lll}\underline{\text { To nauczycielowi }} & \text { oddałem } & \text { książkę. } \\ \text { FM teacher-DAT.FOC } & \text { return-PST.1SING.M } & \text { book-ACC }\end{array}$

(Polish)

'I returned the book to the teacher.' (It's to the teacher that I returned the book)

The same lexical items $n \bar{e}$ and to, which in the glosses to (5) and (6) are referred to as focus markers (FM), function as copulas in non-verbal copular constructions, as in (7) and (8): ${ }^{4}$

$$
\begin{aligned}
& \text { Audì dâlibì } \frac{n \grave{e}}{\text { Audu student.m }} \text { FM.m } \\
& \text { 'Audu is a student.' }
\end{aligned}
$$

2 What has been changed in examples (1)-(3) with respect the original sources of the data is the marking of the focus particles by underlining and of the focused constituent by the use of bold type.

3 The following brief characterization of Hausa is based on Green (2007). It is the most widely spoken Chadic language (official language of Nigeria). Some of its syntactic and morpho-syntactic features are:

(i) lack of morphological case, reliance on word order (ii) predominantly SVO order (iii) a tone language, but having a 'clause-type' intonation, as well (iv) verbal inflection occurs as an independent lexical item preceding the verb (marking person, number, gender agreement with the subject and aspect (tense, mood) of the verb), (v) the inflectional marker has a 'general' form and a 'focus' form, the latter used for wh-questions, focus fronting and relative clauses, (vi) negation involves a discontinuous negative morpheme bá(a) ...ba, (vii) verbs have morphological features reflecting argument structure syntax, (viii) as for NP, specific indefinite determiners, interrogative determiners and distributive universal quantifiers precede the head, whereas definite determiners, genitive phrases, numerals and relative clauses follow the head. Demonstratives, adjective phrases and collective universal quantifiers may optionally precede or follow the head, (ix) a pro drop language allowing also null object NPs with a restriction to non-human referents, (x) classified by Green (2007) as both topic and subject prominent in Li \& Thompson's (1976) classification. Green (2007: 149ff)

${ }^{4}$ The three versions of the focus marker in Hausa are $n \bar{e} / c \bar{e} / n \bar{e}$ representing masculine gender, feminine gender and plural forms, respectively. 
(8)
Adam to student.
Adam-NOM FM student-NOM.SING.M
'Adam is a student.'

Green (2007) puts forth the following structural proposals for (i) ex-situ focus constructions (9a), and (ii) predicational copular sentences in Hausa (9b):

(9) a.

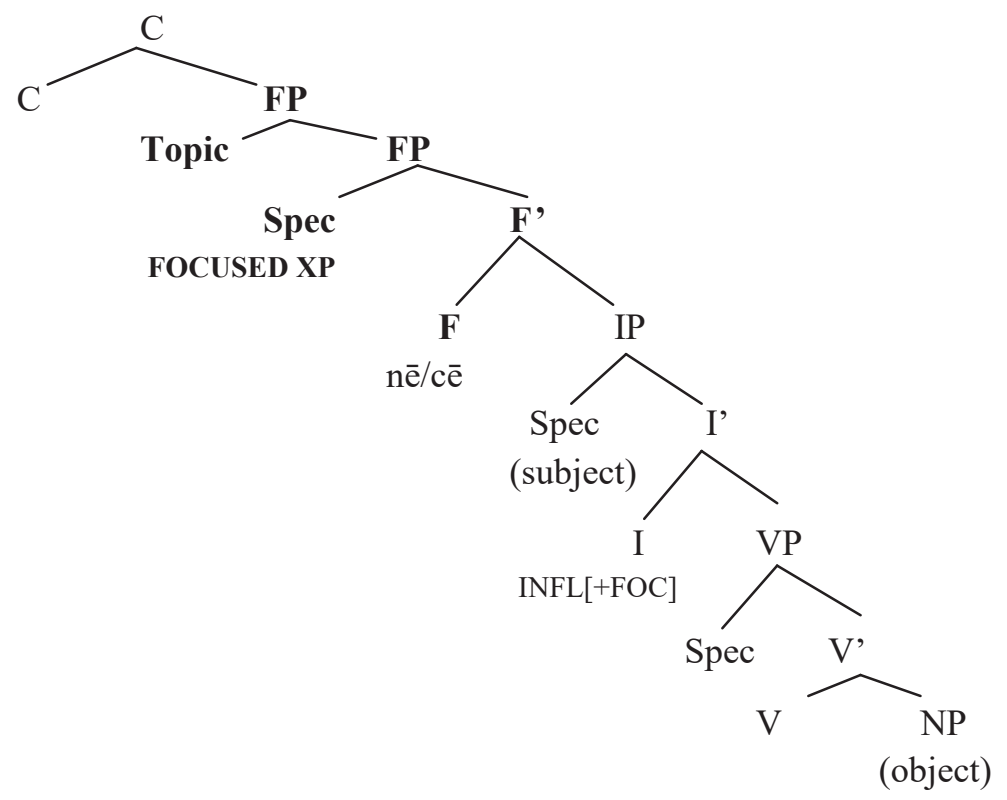

(Green 2007:72)

b.

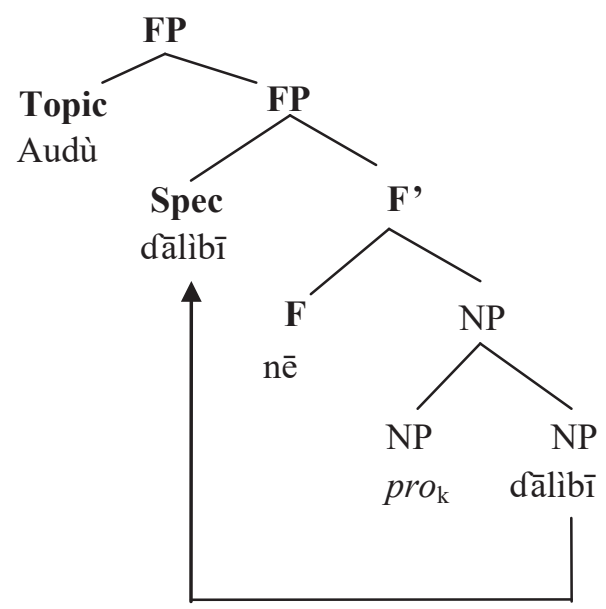

(Green 2007: 140) 
As can be seen in (9), the whole FP projection in both structures is identical, featuring a lexical focus marker $n \bar{e}$ as head.

A way to interpret the observed isomorphism of focus markers and non-verbal copulas attested cross-linguistically is to regard them as two uses of the same syntactic category a zero hypothesis. In what follows, it will be argued that the two occurrences of to in Polish, illustrated in (6) and (8) above, should be analyzed along the lines suggested by Green (2007) for focus markers in Hausa. Specifically, they will be taken to be two instantiations of the same category, with a dual function: of a predicate head and of a focus marker. The theoretical extensions of these ideas proposed below will concern two major points: (i) the nature of the relation between predication and focus, (ii) the syntax of Polish sentences with the particle to in initial and post-topical positions. A related question of the function of to in Polish copular-to clauses, like (8) above, exceeds the scope of this paper and will be left for a separate study. ${ }^{5}$

With respect to point (i), the discussion will dwell on a recent proposal by Kiss (Kiss 2006, 2010) that "focusing is predication", and the idea will be extended to the analysis of focus structures in Polish. As for (ii), arguments will be provided for a unitary, derivational approach to two types of sentences featuring the particle to in two positions: initial (i.e. Polish "to-clefts") and post-topical (i.e. Polish "topic-to sentences").

\subsection{A cross-linguistic excursion. Grammar of focus in Hausa and Polish}

The range of structural similarities between Hausa and Polish with respect to focus constructions is not confined to cases (5)-(8). A list of symmetries is much longer and includes the following:

(i) Both languages allow both in-situ and ex-situ focus strategies.

(ii) The in-situ strategy is preferred for presentational/new information focus in both languages, but it may also be used for contrastive/exhaustive focus.

(iii) The ex-situ strategy is preferred for contrastive/exhaustive focus, but it may also be used for presentational/information focus.

(iv) In wh-movement, fronted wh-phrases may be followed by non-verbal copulas/focus markers: $n \bar{e} / c \bar{e}$ in Hausa, and to in Polish.

(v) Focus markers $n \bar{e} / c \bar{e}$ (in Hausa), and a sentence-initial to (in Polish) do not occur in cases of focus in-situ.

(vi) When topic and focus co-occur in the left periphery, topic precedes focus.

(vii) Parallels between wh-fronting and focus fronting may be observed, so that a uniform analysis for both syntactic types may be suggested.

${ }^{5}$ An anonymous reviewer questions the choice of the constructions for the present analysis saying that it would be more appropriate to compare Polish to-clefts with specificational copular sentences in Polish in which to occurs instead of a verbal copula być ('be'). However, the analysis of copular-to clauses in Polish (both predicational and specificational) with a view of presenting a unified account for the three syntactic types (topic-to, to-clefts and copular-to clauses) could not be confined to the limits of the present paper and therefore has been undertaken in a parallel work (Tajsner 2015). 
(viii) Multiple focus constructions are possible in both languages on condition that both are contrastive.

(ix) It is not possible to have both information focus and contrastive focus in one sentence.

(x) There is no multiple focus fronting. ${ }^{6}$

(xi) There is no simultaneous focus fronting and wh-movement, but either may co-occur with topic fronting.

(xii) Focus fronting constructions share superficial similarities with topic. constructions. Both involve fronting to the left-periphery.

(xiii) The fronted focused phrases may also be verb phrases. ${ }^{7}$

On the other hand, some of the most interesting differences are:

(i) The focus marker $n \bar{e} / c \bar{e}$ follows the focused constituent in Hausa, and the marker to precedes a focused element in Polish.

(ii) There is preference for object resumption for topic constructions in Hausa, while a resumptive strategy is only marginal in Polish. ${ }^{8}$

(iii) The $n \bar{e} / c \bar{e}$ focus marker displays gender and number agreement with the focused phrase which supports the analysis by which there is a Spec-head relationship between a focused phrase and the focus marker. There is no marking of feature agreement on the Polish marker to, which may suggest that the focused phrase and the focus marker do not stay in a Spec-head relationship in Polish;

(iv) Non-verbal copular clauses are formed with NP (DP) subject, and NP (DP) or AP predicate in Hausa, and a non-verbal copula $n \bar{e} / c \bar{e}$, while (arguably) in Polish only NP (DP) predicates can follow a non-verbal copula to in predicational clauses.

Perhaps, nothing is particularly surprising about the comparative facts summarized above. Nevertheless, it seems that at least two points are worth making with respect to the existent parallels between Hausa and Polish. First, they seem to provide a case in favour of universal grammar of focus which, cross-linguistically, comprises such phenomena as parallels between focus and wh-movement, pairing of focus and topic, constraints on multiple focus fronting,

${ }^{6}$ An anonymous reviewer of the paper quite rightly states that it would be worthwhile to examine why there is a restriction on multiple focus fronting but not on multiple wh-movement in Polish. The issue requires a thorough examination, which would have to call upon the typology of multiple wh-questions and the difference between wh-fronting and wh-movement (see Boškovič 2002; Boeckx \& Grohmann 2003). Such an analysis is beyond the scope of this paper. Tentatively, the main idea explored in this paper, namely that ex-situ focus is a (unique) specification predicate (and hence not an operator binding a variable), appears to be compatible with the above difference, as there may be multiple operators but only a single predicate of a given type per clause.

${ }^{7}$ For Polish focus fronting is restricted to infinitive VPs. In Hausa a distinction is made between a verbal noun phrase (VNP) and a verb phrase. The former contains a verbal noun which performs "a function like that of the progressive -ing participle in English", but displays features of a nominalization: noun-like grammatical gender and "the nominative genitive linker before objects." (Green 2007: 13). Both VNP and VP types may be focus-fronted in Hausa.

${ }^{8}$ An anonymous reviewer notes that sentences with resumptive pronouns are outwardly unacceptable in Polish. In that she/he agrees with Rutkowski (2006). However, one could consider examples with a "co do XP"type of topic ('as for XP') like in (i) below:

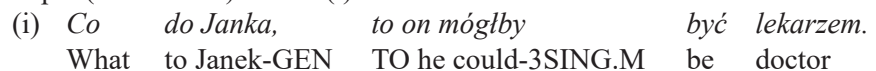

'As for Janek, he could be a doctor.' 
or preference for ex-situ strategy for contrastive focus. The second point is that the part of grammar which handles focus phenomena appears independent of numerous, genetically determined differences between the two languages in the other parts of grammar and the lexicon (see note 3). ${ }^{9}$ A natural way to interpret these analogies would be by reference to the Interface Condition, which imposes constraints on the ways focus phenomena meet the requirements of the external CI and SM systems (as widely discussed in the minimalist literature, e.g. Chomsky 2001; 2007; 2013; Boeckx 2006; Moro 2008; Kosta et al. 2014, among others).

\section{Focusing as predication. Some extension}

Kiss $(2006 ; 2010)$ revises her earlier views on focus in Hungarian by adapting and modifying ideas expressed earlier by Wedgwood $(2003 ; 2006)$. She argues that a focused phrase in Hungarian occupies a Spec. PredP position, as illustrated in (10), below: ${ }^{10}$

$$
\begin{aligned}
& {\left[{ }_{\text {PredP }} P E\right. \text { TER }} \\
& \text { Peter read through the letter } \\
& \text { 'It was Peter who read the letter.' }
\end{aligned}
$$

(Kiss 2006: 12)

The cornerstone of her proposal is the association of specificational predication with exhaustive interpretation. Following Huber (2000) she argues that "a specificational predicate implies that its specification of the individuals that make up the set denoted by the subject is exhaustive, that is, other alternatives are excluded" (Kiss 2006:12). Since identification focus (unlike information focus) denotes exhaustiveness, a natural move is to associate specificational predication with (exhaustive, contrastive) focusing. Hence, instead of postulating a dedicated Spec. FocP phrase as a site of focus, she ascribes this role to the Specifier of the PredP which obligatorily precedes a verb phrase. The type of phrase which can fill this position must be definite or, at least, specific for specificational predication to hold. This is not the only way of filling the Spec. of PredP positon, though. There is an option of placing an indefinite or a non-specific phrase in this position, but then it can only be interpreted as a non-specificational type of predicate, as exemplified in (11)

$$
\begin{aligned}
& \text { János KÖNYVEKET vett meg. } \\
& \text { John BOOKS bought up } \\
& \text { 'It was books that John bought up.' }
\end{aligned}
$$

If identification focus is specificational predication, then a focused phrase in (10) is a Predicate, while the following part of the sentence is Subject of Predication in a classical partition of sentence into Subject and Predicate, as schematically presented in (12):

${ }^{9}$ I can only agree with an anonymous reviewer of this paper who, pointing to the correlation between focus markers and non-verbal copulas in Polish and Hausa, says that "it would be most interesting to search for an even deeper universal at work." This, however, would call for much more space than provided in the limits of this paper.

${ }^{10}$ In her earlier account she advocated a version of the left-peripheral, cartographic view of focus in a template: $\left[_{\text {Top }} \cdots\left[_{\text {Dist }} \cdots\left[_{\text {Foc }} \cdots\left[\left[_{\text {Aspp }} \cdots\left[{ }_{\mathrm{VP}} \ldots\right]\right]\right]\right]\right.\right.$ (Kiss 2003: 23). A driving force for focus-fronting was an uninterpretable [Foc] feature sitting in F, equipped with a strong EPP, so that a focused phrase had to overtly land in the Spec. Foc P. position. 


$$
\text { [PredP }\left[\text { PREDICATE } P E ́ T E R_{\mathrm{i}} \text { ] [vp/SUBJeCt OF PREDICATION } \text { olvasta el a levelet } \mathrm{t}_{\mathrm{i}}\right. \text { ]] }
$$

It can be observed that the structure of predication represented in (12) is an inverse of a more standard view of predication which identifies Subject of Predication with a referential nominal subject of a sentence (DP/NP), and a Predicate with a VP (e.g. Williams 1980; 1987; Rothstein 1983), as in (13), below:

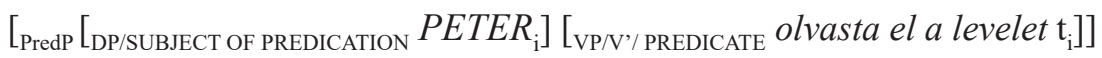

In (13) the subject DP Peter is Subject of Predication, while the VP constitutes the Predicate.

A serious question which remains unaddressed by Kiss $(2006 ; 2010)$, is how one type of predication relates to the other. A standard (Aristotelian) definition of predication has "two central ideas: (a) the syntactic idea that a proposition has a binary structure, with one element, the subject, making reference to an entity and the other expressing a property, and (b) the semantic idea that asserting a proposition involves an act of asserting that an object, the reference of the subject argument, has a property expressed by the predicate" (Rothstein 2006: 73). The representation in (13) expresses this more traditional type of predication, i.e. a property of "having read the letter" (predicate) is ascribed to Peter (Subject). But, there is a question if the property of "being only Peter" (Predicate) can be ascribed to "having read the latter" (Subject), as represented in (12). A basis for such an inverted view may be found in the formulation of predication by a German logician Gottlob Frege (1891; 1892), who understands it as a function of the saturation of expressions; an expression may be saturated or unsaturated, and the latter has an empty position to be filled with a value of variable. Thus, asserting that "it was only Peter that read the letter" may be understood as a saturation of an expression "read the letter" (Subject) "only X (Predicate)". The value provided for the variable is "Peter". Furthermore, such a sentence may be valued as true or false, depending on whether it was actually "only Peter", or "not only Peter" that read the letter (cf. Rothstein 2006: 74). ${ }^{11}$

Thus, it appears that both types of predication illustrated above meet syntactic as well as semantic criteria of predication defined by Frege. This, in turn could suggest that focus sentences like (10) above, should represent a case of "double predication". A proposal of a structural exposition of this might be as suggested in (14), below:

$$
\left.\left[\left[_{\operatorname{PredP}^{2}}\left[P E ́ T E R_{\mathrm{i}}\right]{ }_{\operatorname{Pred}^{1}} \operatorname{Pred}^{2}\left[\operatorname{PredP}^{1 / V P}\left[\operatorname{Pred}^{1} \text { olvasta el a levelet }\right] \mathrm{t}_{\mathrm{i}}\right]\right]\right]\right]
$$

The argument Peter originates in (14) as a Subject of Predication ${ }^{1}$ and ends up as Predicate $^{2}$, while the VP olvasta el a levelet originates as Predicate ${ }^{1}$, but ends up as Subject of Predication $^{2}$.

Kiss (2006) lists out a number of advantages of the new approach to focus, most of which concern greater adequacy in explaining a range of facts about the preverbal part of a sentence in Hungarian (see Kiss 2006: 15-20). Besides, she finds it more economical, as compared with standard cartographic proposals (e.g. Rizzi 1997; 2006; Kiss 2003), on the following grounds:

(i) It needs no $\mathrm{F}$ operator to perform exhaustive identification.

(ii) It needs no FP (FocP) projection and no movement of a designated phrase to SpecFP.

${ }^{11}$ Reference to Aristotle's and Frege's conceptions of predication, based on the discussion in Rothstein (2006), is not part of Kiss's (2006; 2010) argumentation. 
(iii) It needs no $\mathrm{V}$ movement to $\mathrm{F}$.

(iv) The position in which a phrase receives exhaustive interpretation is generated anyhow, for independent reasons, i.e. for predication.

(v) The exhaustive interpretation itself need not be stipulated because it is an attribute of specificational predication.

(cf. Kiss 2006: 17)

The points in (i)-(v) appear persuasive, and hence justify the application of the proposal dubbed "focusing as predication" to the forthcoming analysis of focus structures in Polish. ${ }^{12}$

\section{Polish to-clefts and topic-to sentences. A classical left-periphery approach}

As noted, the type of sentence which is a counterpart of English it-clefts are sentences in which a particle to occurs sentence-initially, e.g.

To PIOTREK $\quad$ napisat $\quad$ list (, nie Tomek).
TO Peter-NOM.FOC
'It waste-PST-3SG.M letter not Tomek

A plausible way to analyze sentences like (15) would be in terms of the extended left periphery with dedicated heads for focus and topic, following the classical Rizzi's (1997) template in which a Top head c-commands FocP. An analysis in this vein is offered in Tajsner (2008) where sentences like (15) are given a structure as in (16) below:

$$
\left[_{\text {TopP }}\left[{ }_{\text {Top }} \text { to }\right]\left[_{\text {FocP }}[\text { Piotrek }]\left[_{\text {Foc }} \text { Foc }_{[+\mathrm{EPP}]}[\text { TP } \text { napisał list }]\right]\right]\right]
$$

Thus, to is given a status of a topic head which at the same time has a function of a focus designator (focus marker, FM). The most local phrase in the c-command domain of to, which occupies the Spec. FocP position, is interpreted as exhaustive or contrastive focus. The type of phrase which may take the Spec. FocP position may be subject, object or adjunct, but not a finite verb, or finite verb phrase (see Tajsner 2008: 354). ${ }^{13}$

${ }^{12}$ As rightly noted by an anonymous reviewer of this article the view of predication as a syntactic category stems from the ideas of Bowers (1993). The cornerstone of this proposal is the postulation of an independent grammatical and morphological category Pred, "whose function it is to relate subject to predicate" Bowers (2003: 25). Bowers (1993) provides empirical evidence that that the inclusion of Predicative Phrase in the structure of English main clauses and small clauses leads to their more satisfactory account and obviates a need for the postulation of functional categories such as light verb (v). The views that "predication is, in a certain sense, the most fundamental relation in both syntax and semantics" and that "though there are many features of natural language systems that one could imagine eliminating without seriously impairing communication, predication is surely not one of them" (ibid) are shared by the author of this article. An extension of Bowers' structural view of predication to the account of sentences with discourse-related functions (such as focus and topic) postulated here, fully accords with a view of predication as fundamental for both syntax and semantics.

${ }^{13}$ Non-finite verb phrases are marginally allowed, as in (i) or (ii):

(i) To pić kawe lekarz mu zabronit, niejeść czekoladę. TO drink.INF coffee doctor him forbid-PST.SG.M, not eat.INF chocolate-ACC 'It is drinking coffee that the doctor forbade him, not eating chocolate.'

(ii) \%To CZYTAĆ Jan musi/będzie ksiażki.

To read Jan-NOM has to/will books-ACC

'It is reading that Jan will/has to engage himself in.'

The latter example comes from Mokrosz (2014) who finds it fully acceptable. 
The other Polish construction to consider are sentences like (17) below, referred to as topic-to sentences:

$\begin{array}{llll}\text { Piotrek } & \text { to } \quad \text { napisat } & \text { LIST. } \\ \text { Peter-NOM } & \text { TO } & \text { write-PST.3SG.M } & \text { letter-ACC.FOC } \\ \text { 'As for Peter, he wrote the letter.' } & \end{array}$

If the status of to as a topic head is maintained for such cases, then a plausible structure for (17) could be (18), below:

$$
\left[_ { \text { TopP } } \text { Piotrek } [ _ { \text { Top } } \text { to } ] \left[_{\text {FocP }}[\text { Piotrek }]\left[_{\text {Foc }} \text { Foc }_{[+\mathrm{EPP}]}[\text { TP Piotrek napisał LIST] }]\right]\right.\right.
$$

The phrase in Spec. TopP is interpreted as topic, while focus is designated in the c-command domain of to, and it may either be the whole FocP (broad interpretation) or a constituent of FocP, e.g. the object (narrow interpretation).

Under the approach presented above, there is an advantageous structural uniformity in the treatment of to-clefts and topic-to sentences in that the topic head to marks a point of orientation: what precedes it is a topic (in Specifier of TopP), what follows it constitutes or contains a focus (FocP). The topic head is immovable, while the phrases on its sides occupy dedicated topic and focus positions. Despite such benefits, the proposal has a few empirical and conceptual disadvantages. First, the structural isomorphism between to-clefts and topic-to sentences appears questionable in view of the fact that adverbs can be inserted after to and before the rest of the sentence in topic-to sentences but no such intrusion is possible in to-clefts, as exemplified below:

$\begin{array}{llll}\begin{array}{l}\text { Piotrek to wczoraj/na pewno } \\ \text { Peter-NOM TO yesterday/for sure }\end{array} \text { write-PST.3SG.M } & \begin{array}{l}\text { LIST. } \\ \text { letter-ACC.FOC }\end{array} \\ \text { 'As for Peter, he certainly wrote a letter yesterday.' } & & \\ \text { *To wczoraj/na pewno } & \text { PIOTREK } & \text { napisat } & \text { list. } \\ \text { TO yesterday/for sure } & \text { Peter-NOM.FOC } & \text { write-PST.3SG.M } & \text { letter-ACC }\end{array}$

Likewise, the inverted modal can immediately follow to in to-topic sentences but not in to-clefts, as shown in (21) and (22) below:

$$
\begin{array}{llll}
\text { List } & \text { to } \text { mógt } & \text { PIOTREK } & \text { napisać. } \\
\text { Letter-ACC } & \text { TO could-3SG.M } & \text { Peter-NOM.FOC } & \text { write.INF } \\
\text { 'As for the letter, PETER could write it.' } &
\end{array}
$$

$\begin{array}{llll}\text { *To mógł } & \text { PIOTREK } & \text { napisać list. } \\ \text { TO could-3SG.M } & \text { Peter-NOM.FOC } & \text { write.INF letter-ACC }\end{array}$

The restrictions observed in cases (19)-(22) may be subsumed under the formula (23):

$\left[_{\text {TopP }} \mathrm{YP}\left[\left[_{\text {Top }} t o\right] \mathrm{XP} / \mathrm{X}\right.\right.$ Focus $\left.]\right]$, while $*\left[_{\mathrm{TopP}}\left[\left[_{\mathrm{Top}} t o\right] \mathrm{XP} / \mathrm{X}\right.\right.$ Focus $\left.]\right]$, where $\mathrm{XP} / \mathrm{X}$ is an adverb or modal.

Next, in to-clefts the focal phrase has to immediately follow to and must be interpreted as exhaustive or contrastive focus (not information focus). For a topic-to sentence, a focal phrase need not be right-adjacent to to, but may still be interpreted as exhaustive focus, as indicated in (24) below: 


$\begin{array}{llll}* \text { To } & \text { Piotrek } & \text { napisat } & \text { LIST } \\ \text { TO } & \text { Peter-NOM } & \text { write-PST.3SG.M } & \text { letter-ACC.FOC }\end{array}$

Piotrek to napisat list do MINISTRA (nie prezydenta).
Peter-NOM TO write-PST.3SG.M letter-ACC to minister-GEN.FOC
'As for Peter, he wrote a letter to the MINISTER (not the president).'

If the function of Spec. Foc P is to accommodate the (narrow) focus phrase, just like the function of Spec. Top phrase is to accommodate topic, then sentences like (25) pose a problem for a left-periphery template analysis of topic-to sentences given in (18). There is no obvious way in which a focused constituent in (25) could be related to the Spec. FocP position in (18).

Another difference between the two types is in the availability of finite verb phrases in a position immediately following the particle to (as already noted, see note 7). Such phrases can appear after to in topic-to sentences but not in to-clefts, as illustrated below:

$$
\begin{array}{lll}
\text { Marek } & \text { to } \left.\left[\ldots \text { VPP }_{\text {napisat }} \text { list }\right]\right] \\
\text { Marek-NOM } & \text { TO } \quad \text { write-PST.3SG.M letter-ACC }
\end{array}
$$

'As for Mark, he wrote a letter.'

$\begin{array}{lll}\text { *to napisat } & \text { list } & \text { Marek } \\ \text { TO write-PST.3SG.M } & \text { letter-ACC } & \text { Marek-NOM }\end{array}$

If the structural conditions in the c-command domain of to in the two types of sentences were the same, as postulated in (16) and (18), then it would be difficult to explain why a finite verb phrase could not fill the position of Spec. FocP in (16).

The observed inadequacies suggest that maintaining a full structural isomorphism between these two types of constructions based on the stable positioning of to as a Top head in a standard Top $>$ Foc configuration of the left periphery may be difficult to sustain and hence calls for a revision, which will be presented in the next two sections.

\section{Polish to-clefts. A revised account}

The following revision of the earlier stance on to-clefts is based on the idea that "focusing is predication", outlined in section 3. The first issue to consider is the mechanics of the derivation of sentence (15). After deriving the TP in a standard fashion, the next step is a merger with a particle to resulting in the formation of (29), below. Crucially, the particle itself is now interpreted as a head of predication Pred ${ }^{0.14}$

$$
\begin{aligned}
& \left.\left[_{\text {Pred }} \text { to }\right]+{ }_{T \mathrm{P}} \text { Piotrek napisał list }\right] \\
& {\left[{ }_{\text {Pred }}\left[{ }_{\text {Pred }} \text { to }\right]\left[{ }_{T P} \text { Piotrek napisał list }\right]\right]}
\end{aligned}
$$

The derivation continues with a selection of a phrase for the Specifier of the PredP. This appears to be a necessary move under the standard assumption that each predication needs

${ }^{14}$ The treatment of to as a Pred ${ }^{0}$ head was earlier proposed by Bondaruk $(2010 ; 2013)$ in her account of Polish copular clauses in which to occurs as a non-verbal copula either instead of, or together with, a verbal copula być ('be'). 
a subject. A trigger for this would be the presence of the EPP feature on a Predicate head. ${ }^{15}$ The choice between the available DPs appears free, because the movement is phase-internal (the DPs are both equidistant from Spec. PredP). ${ }^{16}$ If the subject moves, then (30) is derived, and if the object does, the outcome is (31):17

$$
\begin{aligned}
& {\left[_{\text {PredP }}\left[{ }_{D P} \text { Piotrek }\right]\left[_{\text {Pred }}\left[{ }_{\text {Pred }} \text { to }\right]\left[_{\text {TP }}\left[{ }_{D P} \text { Piotrek }\right] \text { napisał }\left[{ }_{D P} \text { list }\right]\right]\right]\right]} \\
& {\left[_{\text {PredP }}\left[{ }_{D P} \text { List }\right]\left[_{\text {Pred }}\left[{ }_{\text {Pred }} \text { to }\right]\left[_{\text {TP }}\left[{ }_{D P} \text { Piotrek }\right] \text { napisał }\left[{ }_{D P} \text { list }\right]\right]\right]^{18}\right.}
\end{aligned}
$$

Crucially, following Kiss (2006; 2010), it will be assumed that the predicate head to has a potential of creating a form of predication referred to as Specification Predication. A way to interpret this is to ascribe to to a function of a probe with an unvalued, but interpretable feature [+Specification]. The feature would only be valued if matched with an appropriate feature on the goal. ${ }^{19}$

It has to be determined now what sort of feature could match the predicate head to in order to unlock its [+Specification] potential. To this end, consider two pairs of examples (32)-(33) and (34)-(35), below:

$$
\begin{aligned}
& \text { To JANEK zaprosit Magde } \quad \text { (, nie Tomek). } \\
& \text { TO Janek-NOM.FOC invite-PST.3SG.M Magda-ACC not Tomek-NOM } \\
& \text { 'It was Janek who invited Magda (, not Tomek).' } \\
& \text { *to Janek zaprosit MAGDĘ/Magdę. } \\
& \text { To MARYSIA, nie Magda! } \\
& \text { TO Marysia-NOM.FOC not Magda-NOM } \\
& \text { 'It was Marysia, not Magda!' } \\
& \text { *to Marysia, nie MAGDA! }
\end{aligned}
$$$$
\text { TO Janek-NOM.FOC invite-PST.3SG.M Magda-ACC not Tomek-NOM }
$$

15 The instance of predication which is considered now is Predication ${ }^{2}$ (Specification Predication). We assume that the earlier predication, i.e. Predication ${ }^{1}$, uses the same mechanics at an earlier stage of derivation, i.e. movement to Spec.Pred.P ${ }^{1}$ (mapped on the TP) triggered by the EPP feature in Pred $^{0}(\mathrm{~T})$. However, it is assumed here that the status of EPP is derived from the properties of predication, see note 22 .

${ }^{16}$ As noted by an anonymous reviewer, the equidistance of the two DP is preconditioned here by the movement of the object DP to a Spec. vP position. Such a movement is indeed assumed here. See also note 21.

${ }^{17}$ As rightly brought to our attention by an anonymous reviewer, the latter movement avoids Defective Intervention Effects with the DP Piotrek in Spec.TP only under Chomsky's (2008) parallel probing, which is actually assumed here.

${ }^{18}$ Another point raised by an anonymous reviewer is that it should be explained what blocks a possible merger of the object DP list instead of Piotrek in Spec. TP. To tackle the problem, it is assumed here, along the lines of Frampton \& Gutmann's (2002) "crash-proof syntax" that the derivation will avoid such a move because of the potential Case mismatch (the object is ACC, while T checks NOM).

${ }^{19}$ A motivation for introducing this feature in the system comes from a specific functionality of the particle to in to-clefts and topic-to sentences, as well as in copular-to clauses in Polish. Specification is understood here, more broadly, as a semantic feature by analogy to e.g. the feature [+Def] on the article the in English. It makes a matching phrase specified in a sense of selected or designated for a variety of interpretive effects, which are syntactically rendered as predicates. We think, contrary to the anonymous reviewer who raises the issue, that specification in this sense is also present in Polish equative and predicative copular clauses in which to occurs as a copula. For example, in Jorge Mario Bergoglio to Pope Francis ('Jorge Mario Bergoglio is Pope Francis') (equative) and in Janek to artysta ('Janek is an artist') (predicational) the identity/property of the subjects is specified by the bolded phrases which follow to. 
It can be observed that the specification of the right person performed by the two occurrences of to in (32) and (33) is conditioned by the appearance of the focal stress on the constituent following the particle. What is more, in to-clefts the element carrying focal stress needs to be strictly local (right-adjacent) to the probe. The status of to in (34) may seem uncertain - one may argue it is a homophonous demonstrative rather than a predicate head. However, the fact that example (34), repeated as (37), may be used in the context of (36), as shown below, proves otherwise: ${ }^{20}$

$$
\begin{aligned}
& \text { Magda znowu zostawiła bałagan } w \text { pokoju! } \\
& \text { Magda-NOM again leave-PST.3SG.F mess-ACC in room-LOC } \\
& \text { 'Magda again left the room in mess!' }
\end{aligned}
$$

To MARYSIA, nie Magda!

Thus, the feature needed for the specificational potential to be realized is associated with focal stress. Two situations may be considered at this point. First, a focal stress may be placed on the subject DP within TP, as in (38): ${ }^{21}$

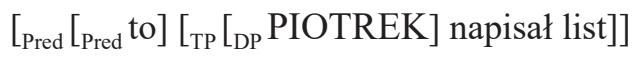

Since, there still is a need to complete a structure for predication, it is possible for the subject, as an option, to move to Spec. Pred.P to check the EPP feature present in Pred ${ }^{0}$, leading to (39): ${ }^{22}$

$$
\left[_ { \text { PredP } } \left[{ }_{D P} \text { PIOTREK] }\left[_{\text {Pred }} \text { to }\right]\left[_{\text {TP }}[\text { DP PIOTREK }] \text { napisał list }\right]\right.\right.
$$

A question that arises at this point is why the specificational potential of the Predicate head to cannot be checked while the DP Piotrek is still in Spec. TP, thus blocking its merger as a specifier of Pred.P. ${ }^{23}$ The answer lies in the property of predication, which, as will be discussed later, should be understood as a function of the saturation of a proposition. ${ }^{24}$ The syntactic relevance of this formula is that after the merger of the head of predication the structure remains unsaturated until an element is merged as a specifier of Pred.P. ${ }^{25}$ Thus, the merger

\footnotetext{
${ }^{20}$ Independently, there are diachronic analyses which argue for the pronominal origin of predicative heads like to. A persuasive analysis in this vein based on diachronic data from Chinese is provided in Rutkowski (2006).

${ }^{21}$ It would have to be explained how focal stress can be articulated in a non-canonical position. This is a separate issue which remains beyond the scope of this paper. There have been different accounts of "stress shifts" in the literature (e.g. Bresnan 1971; Selkirk 1984; Zubizarreta 1998; Reinhart 2006). We incline to a solution based on the idea of a parallel derivation of syntactic and metrical trees, in which stress grids are consecutively added to prosodically most prominent constituents (Adger 2007). Under such an account, roughly, if some constituent is additionally marked with an extra stress grid at the outset of the formation of a metrical tree, it may be spelt out with focal stress, even if it does not initially occupy a canonical phrasal stress position.

${ }^{22} \mathrm{EPP}$ is invoked here as a feature, but its rationale is derived from Bowers' (1993) theory of predication in which EPP is obviated by a requirement of the saturation of expressions, which is an inherent feature of predication. In Bowers (1993: 592n2) "the half of the Extended Projection Principle (EPP) that requires that clauses have subjects can be derived from the general principle that functions must be saturated". Here, such a view of EPP is naturally extended to specification predication to the effect that some phrase has to be merged as a specifier of (specification)Pred.P.

${ }^{23}$ The issue has been raised by an anonymous reviewer.

${ }^{24}$ This is Gottlob Frege's view of predication to be discussed later.

${ }^{25}$ Under Bowers' (1993: 595n2) formulation: “[...] Pr' is uniformly translated in logical form as an unsaturated function $[\ldots]$ ".
} 
of Piotrek in Spec.Pred.P is an indispensable step preventing a derivational crash. ${ }^{26}$ Now, the specificational potential of the Predicate head to cannot be unlocked in the configuration (39) because no matching goal is accessible within the probing domain of the particle to. Thus, the next necessary step must be the movement of the Predicate head to a position from which it could c-command a matching goal, as schematically illustrated below:

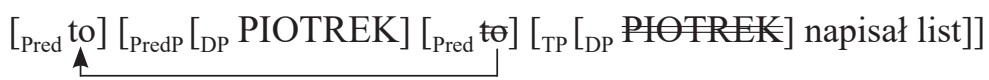

The questions of how the particle to moves to a c-commanding position, and how it is accommodated in the structure are by no means trivial and should be addressed separately, which will be done shortly. Assuming for now that such a move is possible, the configuration allows for the probing of to into Pred.P where the goal, i.e. a focal phrase, can be found and the specificational potential of the Predicate head can be released in sentence (15), repeated below:

To PIOTREK napisat list $\quad$ (nie Janek).
TO Peter-NOM.FOC write-PST-3SG.M letter-ACC not Tom-NOM
'It was Peter who wrote the letter (, not Tom).'

An alternative to the above would be the placement of the focal stress on the object, not subject, as in (41):

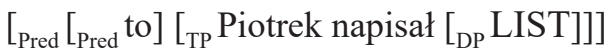

The subject of predication needs to be derived anyhow, and the focal object of TP can be moved to Spec. Pred.P instead, resulting in (42): $:^{27}$

$$
\left[_{\text {PredP }}\left[{ }_{D P} \text { LIST }\right]\left[_{\text {Pred }}\left[{ }_{\text {Pred }} \text { to }\right]\left[_{\text {TP }} \text { Piotrek napisał }\left[_{D P} \text { EIST }\right]\right]\right]\right]
$$

Now, again, there is no focal phrase on which the Predicate head to could check its unvalued [+Specification] feature, hence another instance of internal Merge of to is needed to put it in a c-commanding position with respect to the focal phrase, as in (43) underlying (44):

$$
\left[\left[_{\text {Pred }} \text { to }\right]\left[_{\text {PredP }} \text { LIST [ } \text { Pred }_{\text {Pred }} \text { to } \text { Piotrek napisał } \text { EIST }\right]\right]
$$

\section{To LIST Piotrek napisat. \\ TO letter-ACC.FOC Piotrek-NOM write-PST.3SG.M}

'It was a letter that Piotrek wrote.'

To recap, it is postulated that the derivation of to-clefts has the following three steps: (i) A TP containing a focal phrase is merged with a Predicate head to which has an unvalued [+specificational] feature; (ii) Since predication formed by this merger needs a subject, one of the constituents of TP internally merges with a predicate projection as its specifier. This move is triggered by the presence of the EPP feature on the predicate head; (iii) The predicate head re-merges with the Pred.P, and this, in turn, is in its "enlightened self-interest", because the predicate head still needs to unlock its specificational potential.

${ }^{26}$ It may still be questioned why the checking of the specificational potential by Pred $^{0}$ cannot occur before a merger of the DP in Spec. Pred.P. Instead of assuming some intra-phasal order of events, it may, arguably, be assumed that access to a focal stress is vital at the point of phasal spell-out to PF, thus is checked at the completion of the phase, not earlier.

${ }^{27}$ This movement, presumably, has to use a Spec. vP position, as an "escape hatch" out of the vP phase. 


\subsection{Re-merge of to}

The final stage in deriving to-clefts, as proposed above, is a re-merge of to with the Pred.P, as schematically presented in (45) below:

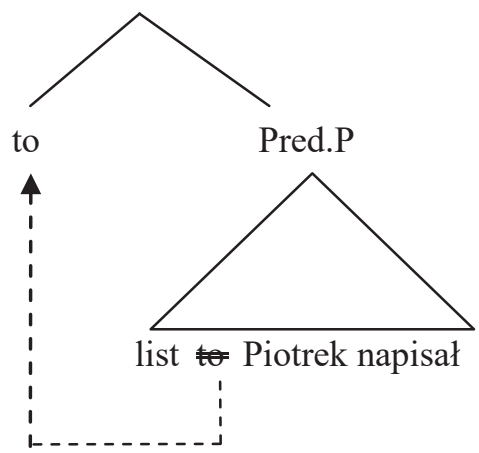

This move may be questionable as an instance of head movement, which is generally excluded from narrow syntax in the standard minimalist framework (Chomsky 1995; 2001). ${ }^{28}$ As discussed by Roberts (2011:7f), Chomsky raises five main objections against head movement: (i) it is semantically vacuous (it has no or minimal effect on LF), (ii) a feature that would trigger head movement would have to be stipulated, unlike features triggering XP movement, (iii) head movement violates Extension Condition, (iv) the moved head does not c-command its trace, a consequence of (iii), (v) head movement is not successivecyclic, since it involves the whole constituent formed at an earlier stage (unless questionable excorporation is allowed). Roberts discusses then three alternatives to the questioned GB-style head movement: (i) treating it as an instance of PF-movement (embarked on by Chomsky 2001), remnant phrasal movement, and (iii) 'reprojective' movement. Of these three, the third appears most suitable to capitalize on for the account of the case of "to-remerge" characterized above.

Reprojection has been a topic of a recent debate (Bury 2003; 2007; Donati 2006; Koeneman 2000; Surányi 2005; 2008; Boeckx 2008; Roberts 2011; Citko 2008; 2011). The leading idea is that, contrary to a standard assumption, it is not always the target of movement which projects. Donati (2006) argues that head movement is always reprojective, which she contrasts with a case in which a $[+w h]$ DP merges with a C to create a CP. She argues that this type of internal Merge is enforced by LF convergence (a need to create a $w h$-question), but in principle it is not the only option. The alternative would be to move a [+wh] $\mathrm{D}$ as

${ }^{28}$ An anonymous reviewer asks for independent motivation for the re-merge of $t o$. We derive it from the properties of predication itself: If $t o$ is $\mathrm{Pred}^{0}$, then the structure of a to-cleft, e.g. (44), without a re-merge of $t o$ would be like in (i):

(i) $\quad\left[{ }_{\text {Pred }}[\right.$ Pred $t o]\left[{ }_{\mathrm{XP}}\right.$ LIST Piotrek napisał list $\left.]\right]$

But (i) is not a legitimate structure for the needs of predication. As noted earlier (note 22), we adopt Bowers' (1993) view that Pr' is an unsaturated function, which naturally aims at saturation. This can be done by merging some phrase in Spec. PredP position and forming the necessary subject-predicate alignment. But, fulfilling this condition by the merger of the focal phrase LIST, which is a free option, calls for an instance of re-merge of to in a position c-commanding PredP for the needs of linearization. 
a head, but then the resultant structure would have to be DP, which could not be interpreted as a $w h$-question. It could, however, be interpreted as a free relative clause, as in (46), below:

$$
\text { I will visit [what] you will visit. }
$$

(Roberts 2011: 24)

Thus, there is no restriction on head movement itself. If it can merge with an XP, as a free derivational option, it avoids the problems with Extension Condition, c-command of the copy and successive-cyclicity. As noted by Citko (2008: 122f), although "it is true that $[$ head $]$... movement ... does not establish a spec-head feature checking ... the computational system does not impose any restrictions on labels created by both External and Internal Merge operations".

What remains is a question of LF convergence, but, as evident in (46), there is a natural interpretation of the outcome of the head movement of $[+\mathrm{wh}] \mathrm{D}$ as a free relative. There are other arguments in favour of semantically relevant head movement, e.g. Lechner (2006) discusses cases in which head-moved modals take scope over quantifiers. Another case at hand is subject-auxiliary inversion for changing the force of a clause from declarative to interrogative. Thus, it seems that it may be safely assumed that an instance of reprojection illustrated in (43) may have LF relevance, as well.

\section{Topic-to sentences in Polish}

As noted, the predicate head to is operative in Polish not only in the case of to-clefts described above but also in constructions referred to as topic-to sentences, exemplified by (47) below: ${ }^{29}$

$$
\begin{array}{ll}
\text { Piotrek to napisat } & \text { LIST. } \\
\text { Peter-NOM TO write-PST.3SG.M letter-ACC.FOC } \\
\text { 'As for Peter, he wrote the letter.' }
\end{array}
$$

Assuming syntactic uniformity, it may be argued that up to a point the derivation of topic-to sentences is identical to the derivation of to-clefts. Thus, structure (36) is repeated below as (48):

$$
\left[_{\text {Pred }}\left[{ }_{\text {Pred }} \text { to }\right]\left[_{\mathrm{TP}}[\mathrm{DP} \text { Piotrek }] \text { napisał }\left[\mathrm{DP}_{\mathrm{DP}} \text { LIST }\right]\right]\right]
$$

Since a constituent has to be raised to the Spec. Pred.P position to become Subject of Predication, an option is to move a non-focal Subject of TP, resulting in (49), below:

$$
\left[_{\text {PredP }}\left[{ }_{D P} \text { Piotrek }\right]\left[_{\text {Pred }} \text { to] }\left[_{\text {TP }} \text { Piotrek napisał [DP LIST] }\right]\right]\right.
$$

The focal stress on the object may be assigned in situ by a default Nuclear Stress Rule (as originally formulated by Halle \& Vergnaud (1987), and then revised by Cinque (1993), Zubizarreta \& Vergnaud (2005), Reinhart (2006), Adger (2007)). In such a case, the constituent which bears it, would still be in a c-command domain of the Predicative head to, so

${ }^{29}$ In Tajsner \& Cegłowski (2006) this construction is called True Topicalization and compared with the cases of Object Fronting, in which an object DP is also interpreted as topic, but does not move to a dedicated Spec. TopP, but rather to a lower position - an outer Spec. TP position. In sentences formed by Object Fronting, e.g. List Piotrek napisat (letter Piotr wrote, 'Piotr wrote the letter'), there is not a particle to following the topic. 
that its specificational potential can be unlocked (even though it is not right-adjacent to to). As a result, sentence (50) below, can be interpreted as Specification Predication (involving exhaustive listing), and the type of focus in (50) could be interpreted as exhaustive, as indicated in the following exchange in (51). ${ }^{30}$

Piotrek to napisat LIST. (=45)

A: Piotrek wystat maila do ministra?

Piotrek-NOM send-PST.3SG.M. mail-ACC to minister-GEN

A: 'Did Peter send a letter to the minister?'

$\begin{array}{clll}\text { B: Nie, Piotrek } & \text { to } \text { napisal } & \text { LIST, } & \text { nie maila. } \\ \text { No Piotrek-NOM } & \text { TO write-PST.3SG.M } & \text { letter-ACC.FOC } & \text { not mail-ACC }\end{array}$

B: 'No, Peter wrote a letter, not an e-mail.'

The answer in (51) represents narrow focus, which is always an instance of exhaustive focus (cf. Selkirk 1995; Reinhart 2006; Büring 2006).

The scenario changes a little if the object is additionally scrambled (presumably by object shift to Spec. vP, cf. Belletti (2004)) to a pre-verbal position. ${ }^{31}$ In such a case, it would be placed in a more local relation with a Predicate head and the specificational potential of the latter could again be discharged, as indicated by the use of (52) in the exchange (53):

$\begin{array}{lll}\text { Piotrek } & \text { to } \text { LIST } & \text { napisat. } \\ \text { Peter-NOM } & \text { TO letter-ACC.FOC } & \text { write-PST.3SG.M } \\ \text { 'As for Peter, he wrote a LETTER.' } & \end{array}$

A: A więc Piotrek napisat MAILA?

A: 'So, Peter wrote an e-mail?'

B: Piotrek to LIST napisal (, nie maila).

B: 'Peter wrote a LETTER (, not an e-mail).'

However, it should be noted that exhaustive interpretation of the scrambled object is not obligatory even if it is brought to a local relation with to, as in (52). An option of interpreting it as new information focus is still open, as illustrated by the possible exchange in (54):

${ }^{30}$ However, there are two important points to make. First, exhaustive focus exists in Polish as an option even in the absence of the lexical particle to. For example, a cleft sentence: To LIST wystat Piotrek, nie maila ('It was a letter that Peter sent, not an e-mail') may alternatively be rendered as: Piotrek wysłał LIST, nie maila ('Peter sent a letter, not an e-mail') preserving the exhaustive listing interpretation. Thus, specificational predication is not pre-conditioned by the presence of a lexical head of specificational predication. The question of the actual nature of exhaustive focus beyond to-clefts is outside the scope of the present paper (for discussion see Tajsner 2008). The second point is that sentence (50) need not be interpreted as involving exhaustive listing, there is an option that the focal phrase just represents VP-broad information focus, as indicated by the exchange: (i) A: A co zrobił Piotrek? (A: 'And what did Peter do?') B: Piotrek to napisał LIST. (B: 'Peter wrote a LETTER.'). We assume, that in such a case the specificational potential of to extends to the whole clause or to the VP.

${ }^{31}$ The whole controversy on the nature of scrambling is left aside (e.g. Saito 1992; Boškovič \& Takahashi 1998; Baylin 2001; Miyagawa 2003; Boškovič 2004), specifically the question if scrambling is semantically vacuous or functionally relevant, EPP-triggered or optional, base-derived or a result of Internal Merge. 
A: A cóż Piotrek zrobit?

A: 'And what did Peter do?'

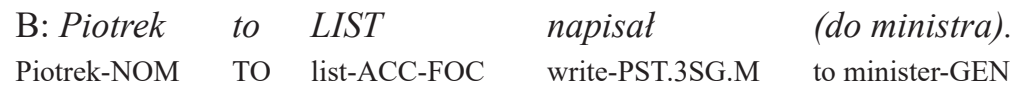

B: 'Peter wrote a LETTER (to the minister).'

The reason for the non-exhaustive interpretation of the scrambled object in (54B) may be that the specification extends here to the whole TP, rather than to its single constituent (see note 30 ). ${ }^{32}$

\section{Extensions and modifications}

\subsection{New information focus as specification}

The implication arising from the considerations in the preceding section is that specificational predication need not always be linked with exhaustive listing, which is a modification of Kiss's $(2006 ; 2010)$ original idea. Under such an extension, advocated here, specification would be understood more broadly, as a way of partitioning sentence structure into discourse-related chunks associated with topic and focus. This idea can be linked to a widely held view that Topic/Comment and Focus/Background asymmetries are universal and unique features of human language, precursors of Subject/Predicate structures (cf. e.g. Jackendoff 2002; Krifka 2007). ${ }^{33}$ Adopting this view, the presence of Specification Predicate Phrases in the derivation can be seen as a way of grammaticalization of such asymmetries and a way of meeting Bare Output conditions at the same time.

\subsection{Predication, Internal Merge and saturation of expressions}

From a different perspective, the existence of Specification Predication would correspond to the duality of semantics (thematic structure vs. discourse structure (e.g. Chomsky 2007; Hinzen 2008), so that while thematic (argument) structure is linked to a standard form of predication $\left(\right.$ Predication $\left.^{1}\right)$, then specification predication $\left(\right.$ Predication $\left.^{2}\right)$ is a syntactic handling of discourse structure. There is a direction in which one can suggest a further extension of the idea that focusing is predication. As noted above, under Frege's definition below:

${ }^{32}$ As noted by an anonymous reviewer, it still remains to account for the derivation of sentences like (i)
(i) List
to PIOTREK
napisat,
a nie Marek
Letter-ACC TO Piotrek-NOM.FOC write-PST.3SG.M and not Marek-NOM
'As for the letter, it was Piotrek who wrote it, not Marek.'

In this case, the focal phase stays in situ (Spec. TP) and the object merges in Spec. PredP (raises directly from Spec.vP to Spec. Pred.P, as allowed by equidistance and avoiding Defective Intervention Effects, as noted earlier, see notes 16 and 17).

${ }^{33}$ As stated by Jackendoff (2002): "The cognitive salience of the topic-comment form, I suspect, is what gave rise to the Aristotelian formulation of logic in terms of predicates applied to subjects." Jackendoff (2002: 413). 
of predication, for an expression to be saturated a value has to be assigned to a variable, which itself is part of the expression. But there is a question of how a variable becomes a part of an expression in the first place. Syntax provides two basic ways for the expansion of expressions, External Merge and Internal Merge. Under standard minimalist assumptions variables (gaps, silent copies) are not lexical items, hence they cannot be introduced to structure through External Merge. This leaves only Internal Merge. So, a syntactic basis for predication, understood as a function of the saturation of expressions through variable resolution, is Internal Merge. Such a role of Internal Merge appears to apply to both forms of predication distinguished above. For Predication ${ }^{1}$, linked with thematic structure, there is a need for Internal Merge to apply in order to form a predicate-argument opposition, as illustrated in (55) and (56) below: ${ }^{34} 35$

$$
\begin{aligned}
& \text { [PREDICATION1 John [[John] [sleeps]] } \\
& \text { [PREDICATION1 }_{\text {[value of X] }][[\underbrace{\text { X sleeps }]]}_{\text {saturation }}}
\end{aligned}
$$

Once the structure for thematic predication is completed there may arise a need for the syntactic representation of discourse structure. To this end, a head of a Predication ${ }^{2}$ merges with the existent structure, as schematically shown in (57) below, which has to be followed by Internal Merge to form a syntactic basis for saturation, as in (58):

$$
\begin{aligned}
& \operatorname{Pred}^{2}+\left[{ }_{\mathrm{YP}} \ldots \mathrm{XP} \ldots\right] \\
& {\left[\text { PREDICATION2 } \mathrm{XP}\left[\operatorname{Pred}^{2}\left[{ }_{\mathrm{YP}} \ldots \mathrm{XP} \ldots\right]\right]\right]}
\end{aligned}
$$

\subsection{Partitioning options}

Thus, a specifying head is $\operatorname{Pred}^{0}$ (instantiated in Polish by to), and the part specified by it is associated with the interpretation as some form of focus (exhaustive, contrastive, or informational) and the remaining part would be interpreted as topic (background). The three options of such a partitioning are schematically presented in (59), (60) and (61), below:

$$
\begin{aligned}
& \left.\left.\left[\text { PredP TOPIC [ [ }{ }_{\text {Pred }} \text { to }\right]\left[_{\mathrm{XP}} \text { FOCUS }\right]\right]\right] \\
& {\left[_{\text {PredP }} \text { TOPIC [ [ } \text { Pred } t o\right]\left[_{\mathrm{XP}}(\mathrm{TOPIC})\left[_{\mathrm{YP}} \text { FOCUS }\right]\right. \text { (TOPIC)]]] }} \\
& {\left[_{\text {Pred }}[\text { Pred } t o]\left[_{\text {PredP }}[\text { YP FOCUS }]\left[\left[_{\text {Pred }} t 0\right] \text { TOPIC }\right]\right]\right]}
\end{aligned}
$$

${ }^{34}$ It will be assumed that the formation of the structure needed for predication is mapped on the projections of functional heads such as $v$ (light $\mathrm{v}$ ) and $\mathrm{T}$, as in the standard minimalist derivation. Thus, the categorial representation of Predication ${ }^{1}$ in (55) would be (i):

(i) $\left[_{\mathrm{TP}} \operatorname{John}\left[\mathrm{T}\left[{ }_{\mathrm{vP}}\right.\right.\right.$ John $[\mathrm{v}[\mathrm{VP}$ sleeps $\left.\left.\left.]]\right]\right]\right]$

${ }^{35}$ A possible complication may be that, depending on the type of predicate, the saturation of expressions for Predication ${ }^{1}$ may require more than one turn of Internal Merge. Thus, e.g. for a transitive predicate (e.g. kiss) Internal Merge may have to apply twice, with two turns of saturation for two arguments. This would call for a revision of the standard derivation for transitives. An alternative would be to limit Predication ${ }^{1}$ to the SubjectPredicate opposition, excluding internal arguments. The issue is left open. 
Option (59) represents a case of a topic-to sentence in which the whole phrase following to is interpreted as focus. ${ }^{36}$ If the XP of (59) is a TP, then phrasal stress is typically assigned in situ (by NSR), and the interpretation of its (broad) focus is new information. ${ }^{37}$ An instantiation of (60) would be example (47) above, used in a context of a question like (62) below (see note 30$):^{38}$

\section{A co zrobit Piotrek?}

'And what did Peter do?'
Piotrek to napisat
LIST.
Peter-NOM TO write-PST.3SG.M letter-ACC.FOC
'As for Peter, he wrote the letter.'

Option (60) represents an instance of a topic-to sentence in which a selected phrase within XP is in narrow focus and the interpretation is obligatorily exhaustive (or contrastive). Finally, (61) is a case of a to-cleft with the YP in narrow focus interpreted exhaustively (or contrastively).

\section{Advantages of the analysis}

There are a few important benefits of the above presented approach to the two types of Polish clauses with the occurrence of a particle to. First, it allows to explain the restriction formulated in (23) above, on the occurrence of sentence adverbs and modals after to in $t o$-clefts but not in topic-to sentences. The restriction finds a straightforward explanation if there is a difference in structure between the two types, as postulated above. In topic-to sentences, to takes a sentential projection TP or a ForceP as its complement. ${ }^{39}$ This allows for TP-adjoined adverbs and inverted modals to immediately follow the particle to. In toclefts, to is re-merged above the Spec. Pred.P excluding an option for adverbs or modals to appear immediately after to.

${ }^{36}$ Structure (59) would also be representative for copular-to clauses in Polish like (8) above, repeated below, in which to is a non-verbal copula replacing the form of the verbal copular 'be'.

(8) Adam to student.

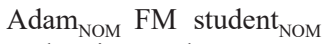

'Adam is a student.'

${ }^{37}$ The XP of (59) may also be a ForcePhrase with a dislocated wh phrase bearing focal stress, like (i):

(i) Piotrek, to co napisat?

Peter to what wrote

'As for Peter, what did he write?'

${ }^{38}$ But, in situ focus (by NSR) is not the only option for pattern (59), as observed above with reference to (52).

${ }^{39}$ In Polish, wh-phrases appear below a complementizer in embedded wh-questions like (i) below:

(i) Myślisz, że kogo Janek zaprosi?

think $_{2 \text { nd,Sing,Pres }}$ that whom Janek invite ${ }_{\mathrm{FUT}}$

'Who do you think Janek will invite?'

This shows there is a Specifier position (Spec. XP) below a Fin/C (complementizer) head and above the TP for the wh-phrase in a structure:

(ii) $\left[\begin{array}{c}\mathrm{FinP} / \mathrm{CP} \\ {[\mathrm{Fin} / \mathrm{C}}\end{array}[\mathrm{Fin} / \mathrm{C} \dot{\mathrm{Z} e}] \ldots\left[\mathrm{XP}\right.\right.$ wh- $\left.\left.\left[_{\mathrm{TP}} \ldots\right]\right]\right]$

$\mathrm{XP}$ will, tentatively, be associated here with the ForceP. 
Next, it becomes possible to explain why there is a difference between the two syntactic types in the way a constituent is designated for a focus interpretation by the particle to. As noted above, in to-clefts the focused constituent has to be adjacent to the particle, while in topic-to clauses it may be any phrase within its c-command domain. This is the necessary outcome of the proposed derivation; to-clefts are exactly the cases in which a focal phrase is raised to a position of Spec. Pred.P, as a free option. If this happens, however, the next step must be a re-merge of to in the closest c-commanding position for the discharge of its unvalued [+Specification] potential. And the position it takes after re-merge is necessarily right-adjacent to the focal phrase sitting in Spec. Pred.P. Nothing like this has to happen in topic-to sentences, in which a non-focal phrase is raised to Spec. Pred.P, and the particle to (a specificational predicate head $\operatorname{Pred}^{0}$ ) finds a focal phrase in its c-command domain without having to re-merge.

Furthermore, it becomes obvious, under the present account, why the focused phrase in topic-to sentences need not occupy the dedicated Spec. FocP position in a left-periphery account of examples like (17) above, repeated below, with the alleged structure in (18):

$\begin{array}{llll}\text { Piotrek } & \text { to } & \text { napisat } & \text { LIST. } \\ \text { Peter-NOM } & \text { TO } & \text { write-PST.3SG.M } & \text { letter-ACC.FOC } \\ \text { 'As for Peter, he wrote the letter.' } & \end{array}$

$$
\left[_ { \text { TopP } } \text { Piotrek } [ _ { \text { Top } } \text { to } ] \left[\text { FocP } [ \text { Piotrek } ] \left[_{\text {Foc }} \text { Foc }_{[+E P P}\left[\left[_{\mathrm{TP}} \text { Piotrek napisał LIST] }\right]\right]\right.\right.\right.
$$

The reason is that to does not take a dedicated FocP as complement at all, as given in (63), and thus any phrase within TP (as well as the whole TP) can be subjected to a focus interpretation at the C-I interface:

$$
\left[_{\text {PredP }}\left[{ }_{\mathrm{DP}} \text { Piotrek }\right]\left[_{\text {Pred }} \text { to }\right]\left[_{\mathrm{TP}} \text { Prek napisal }\left[{ }_{\mathrm{DP}} \mathrm{LIST}\right]\right]\right]
$$

Finally, the alternative approach is able to explain why finite verb phrases are excluded from appearing in a position designated for a focus interpretation in to-clefts but not in topic-to sentences. As noted above, the restriction does not extend to infinitive verb phrases, as illustrated below:

$$
\begin{array}{lllll}
\text { *to } & \text { TANCZYE } & \text { Marek, } & \text { nie śpiewat } \\
\text { TO dance-PST.3SG.M.FOC } & \text { Marek-NOM, not } & \text { sing-PST.3SG.M }
\end{array}
$$

$$
\begin{array}{llll}
\text { To TANCZYĆ } & \text { Marek } & \text { odmówit, } & \text { nie śpiewać. } \\
\text { TO dance.INF.FOC } & \text { Marek-NOM } & \text { refuse-PST.3SG.M } & \text { not sing.INF }
\end{array}
$$$$
\text { 'It was dancing that he refused, not singing.' }
$$

For a verb phrase to be designated for a focus interpretation in to-clefts it would have to first get merged in the Spec. Pred.P position starting from a configuration like (66) below:

$$
\left[_ { P r e d } \text { to } \left[{ }_{T P}\right.\right. \text { Marek TAŃCZYŁ]] }
$$

However, there is substantial evidence that a finite verb in Polish overtly raises at least from $\mathrm{V}$ to $\mathrm{v}$, and probably higher to $\mathrm{T} .{ }^{40}$ If so, then a position from which a Polish finite verb

${ }^{40}$ For example, Murakami (2011) argues that a factor responsible for the movement of all finite verbs to $\mathrm{T}$ in Polish (as well as in other European languages and earlier English) is the presence of the feature [Mood], Szczegielniak (1997) argues for a PF verb movement to T, and Witkoś (2007) and Wiland (2008) for overt syn- 
could move to Spec. Pred.P could only be a lower head position (v or T). Thus, the derivation would have to include a case of "improper" (X to YP) Internal Merge. ${ }^{41}$ Independently, a VP with a vacated head position could not undergo Internal Merge in Spec. Pred.P. These two factors jointly exclude an option of a finite verb phrase merging in Spec. Pred.P under the analysis advocated here, and further, prohibit the finite VP from appearing to an immediate left of the particle to in to-clefts, as in (64) above.

The situation with an infinitive verb phrase is different. The evidence for a finite (or a non-finite past Participle) verb movement to Tense is usually contrasted with evidence for the lack of such a movement for infinitive verbs. ${ }^{42}$ If, then the verb need not be raised to $\mathrm{T}$ in syntax or PF, then the whole VP (or vP, after the external argument merges in Spec. TP) can merge in the Spec. Pred. P. giving rise to structures like (65).

Another advantage of the proposed approach is that it is consistently derivational and the existent parallels as well as the discrepancies between the two types of constructions considered, i.e. to-clefts and topic-to sentences, result from different choices from the set of the available derivational options. Also, there is no questionable discourse-linking of the categories designated for topic and focus interpretations, as these are left for the interpretive C-I system to determine. Finally, one could repeat, after Kiss (2006: 17), two further conceptual advantages of the approach dubbed focusing as predication adapted and modified here: (i) it does not need the special machinery of the dedicated left-periphery, specifically: it needs no F operator, no FP (FocP) projection, no movement of a designated phrase to SpecFP, and no $\mathrm{V}$ movement to $\mathrm{F}$, (ii) it derives the properties of focus constructions from a more general syntactic scheme which is syntactic predication. More specifically, the posi-

tactic V-to-v movement (prior to remnant VP movement). If finite V-to-T movement is purely a PF phenomenon, as hypothesized in Chomsky (1995), then still the observed constraint on a merge of a finite VP in Spec. Pred.P holds: if a verb is to move at PF to T, it cannot get syntactically merged in a higher Spec. Pred.P position.

${ }^{41}$ Note that an option of Re-Merge (reprojective head movement) would for (66) result in the formation of another verbal projection:

(i) [V TAŃCZYŁ [Pred to [ ${ }_{\mathrm{TP}}$ Marek tańezyt] $\left.]\right]$

The problem with structure (i) is that the EPP feature on a Pred0 head would not be checked without projecting a Spec.PredP position and filling it with an XP. Hence, reprojection of the verb is not regarded as a derivational option here.

${ }^{42}$ For example, there is evidence for non-finite Participles rising in Polish to Tense to pick up verbal inflection (Borsley \& Rivero 1994; Szczegielniak 1997):
(i) Kiedy czytałeś
te
książkę?
when read-PST.2SG.M this-SG.F book-ACC
'When did you read this book?'

(ii) Kiedyś czytat książę?

when-2SG.M read-PST.M this-SG.F book-ACC

In (i) the verb raises, while in (ii) it does not, hence $\varphi$ features are spelt out on the wh-word. No such movement is possible for infinitive verbs, though, as seen in (iii) below:
(iii) *Kiedy przeczytać byś

$$
\text { mógt }
$$ when read-INF.PRF.SBJV.2SG could-M this
(iv) Kiedy mógłbyś przeczytac te when could-SBJV.2SG.M read-INF.PRF this book-ACC 'When could you read this book?'
(v) Kiedybyś mógt przeczytać tę książkę? when that-SBJV.2SG could-M read-INF.PRF this book-ACC 'When could you read this book?'


tion in which phrases receive discourse-related interpretation as focus or topic (i.e. Spec. Pred.P) is generated anyhow, for independent reasons, i.e. for predication.

\subsection{Summary and conclusion}

The main purpose of the foregoing discussion has been to outline the analysis of two types of Polish constructions used for expressing focus and topicality, so called to-clefts and topic-to sentences. What links these two is, apart from functional properties, the use of a particle to, which has a potential of designating a focal phrase in its c-commanding domain for a special (focus) interpretation in the C-I system. Following Kiss (2006; 2010) it has been postulated that the appropriate syntactic configuration is not built around a leftperiphery, dedicated Focus head, but involves a formation of a Predicative Phrase which is independently needed to express a form of predication referred to Specification Predication. The particle to has been identified as an overt predicate head $\operatorname{Pred}^{0}$ in Polish, which takes TP (or ForceP) as its complement and may, if a need arises, undergo an instance of re-Merge. A designation of a phrase for special (focus) interpretation is done through valuation of the [+Specification] feature on Pred $^{0}$ and can be performed from two locations: from the head position of Pred.P in topic-to sentences, and from a re-projected position in to-clefts.

The role of the initial comparison of Polish and Hausa has been to show that these two genetically unrelated language systems share a significant part of the universal grammar of focus. The key point, however, has been the observed isomorphism of focus markers and non-verbal copulas in the two languages. This, in turn, has led to promoting a unitary structural approach to sentences with lexical focus markers, analyzed above, and non-verbal copular-to sentences like (8) above, in Polish. Such an approach appears possible if the particle to is uniformly analyzed in all these syntactic types as $\mathrm{Pred}^{0}$, a head of Specification Predicative Phrase. The analysis of Polish non-verbal copular-to clauses along these lines exceeds the scope of the present proposal and is left for a separate study.

\section{References}

Adger, David. 2007. Stress and phasal syntax. Linguistic Analysis 33. 238-266.

Bailyn, John. 2001. On scrambling: A reply to Boskovic and Takahashi. Linguistic Inquiry 32(4). 635-658.

Belletti, Adriana. 2004. Aspects of the low IP area. In Rizzi, Luigi (ed.), The structure of CP and IP. The cartography of syntactic structures, Vol. 2, 16-51. Oxford: Oxford University Press.

Boeckx, Cedric. 2006. Linguistic minimalism: origins, concepts, methods, and aims. Oxford: Oxford University Press.

Boeckx, Cedric. 2008. Bare syntax. Oxford: Oxford University Press.

Boeckx, Cedric \& Grohmann, Kleanthes K. (eds.). 2003. Multiple WH-fronting. Amsterdam: Benjamins.

Bondaruk, Anna. 2010. To as averb or as a pronoun: The case of Polish copular constructions. In Cyran, Eugeniusz \& Szymanek, Bogdan (eds.), Verb structures: Between phonology and morphosyntax, 53-73. Lublin: Wydawnictwo KUL.

Bondaruk, Anna. 2013. Copular clauses in English and Polish. Lublin: Wydawnictwo KUL.

Borsley, Robert \& Rivero, Maria-Luisa. 1994. Clitic auxiliaries and incorporation in Polish. Natural Language and Linguistic Theory 12. 373-423.

Bošković, Željko. 2002. On multiple wh-fronting. Linguistic Inquiry 33(3). 351-383

Bošković, Željko. 2004. Topicalization, focalization, lexical insertion, and scrambling. Linguistic Inquiry 35. 613-638. 
Bošković, Željko \& Takahashi, Daiko. 1998. Scrambling and last resort. Linguistic Inquiry 29. 347-366.

Bowers, John. 1993. The syntax of predication. Linguistic Inquiry 24(4). 591-656.

Bowers, John. 2003. Predication. In Baltin, Mark \& Collins, Chris (eds.), Handbook of contemporary syntactic theory. Blackwell Publishing, 2003. Blackwell Reference Online. 12 May 2007.

Bresnan, Joan. 1971. Sentence stress and syntactic transformations. Language 47. 257-281.

Büring, Daniel. 2006. Focus projection and default prominence. In Molnar, Valéria \& Winkler, Susanne (eds.), The architecture of focus, 321-346. Berlin: Mouton De Gruyter.

Bury, Dirk. 2003. Phrase structure and derived heads. London: University College London. (Doctoral dissertation.)

Bury, Dirk. 2007. Verb movement and VSO-VOS alternations. UCL Working Papers in Linguistics 19. 77-91.

Chomsky, Noam 1995. The Minimalist Program. Cambridge, MA: MIT Press.

Chomsky, Noam. 2001. Beyond explanatory adequacy. In Belletti, Adriana (ed.), Structures and beyond: The cartography of syntactic structure, Vol. 3, 104-131. Oxford: Oxford University Press.

Chomsky, Noam. 2007. Approaching UG from below. In Sauerland, Uli \& Gärtner, Hans-Martin (eds.), Interfaces + Recursion = Language? Chomsky's Minimalism and the view from semantics, 1-29. Berlin: Mouton de Gruyter.

Chomsky, Noam. 2008. On phases. In Freidin, Robert \& Otero, Carlos P. \& Zubizarreta, Maria Luisa (eds.), Foundational Issues in Linguistic Theory, 133-166. Cambridge, MA: MIT Press.

Chomsky, Noam. 2013. Problems of projection. Lingua 130. 33-49.

Cinque, Guglielmo. 1993. A null theory of phrase and compound stress. Linguistic Inquiry 24. 239-297.

Citko, Barbara. 2008. Small clauses reconsidered: Not so small and not all alike. Lingua 118. 261-295.

Citko, Barbara. 2011. Symmetry in syntax: Merge, move and labels. New York: Cambridge University Press.

Donati, Caterina. 2006. On wh-head movement. In Cheng, Lisa Lai-Shen \& Corver, Norbert (eds.), Wh- movement: Moving on, 21-46. Cambridge, MA: MIT Press.

Frajzyngier, Zygmunt. 1993. A grammar of Mupun. Berlin: Dietrich Reimer.

Frampton, John \& Gutmann, Sam. 2002. Crash-proof syntax. In Epstein, Samuel David \& Seely, T. Daniel (eds.), Derivation and explanation in the minimalist program, 90-105. Malden, MA: Blackwell Publishers.

Frege, Gottlob. 1891. Function and concept. In Geach, Peter \& Black, Max (eds.), Translations from the philosophical writings of G. Frege. 1980 edn. 21-41. New York: Rowman and Littlefield.

Frege, Gottlob. 1892. Concept and object. In Geach, Peter \& Black, Max (eds.), Translations from the philosophical writings of G. Frege. 1980 edn. 42-55. New York: Rowman and Littlefield.

Green, Melanie. 2007. Focus in Hausa. Oxford: Blackwell Publishing.

Halle, Morris \& Vergnaud, Jean-Roger. 1987. An essay on stress. Cambridge, Mass.: MIT Press.

Hinzen, Wolfram. 2008. Prospects for an explanatory theory of semantics. Biolinguistics 2(4). 348-363.

Hornstein, Norbert. 2009. A theory of syntax: Minimal operations and Universal Grammar. Cambridge: CUP.

Huber, Christian. 1999. Issues in syntax and interpretation of Sumerian clauses. In Proceedings of Workshop on diachronic and synchronic variations in the phonology, morphology, and syntax of Sumerian. Oxford: Oriental Institute.

Huber, Stefan. 2000. Es-Clefts und det-Clefts. Zur Syntax, Semantik und Informations- struktur von Spaltsätzen im Deutschen und Schwedischen. Stockholm: Almquist and Wiksell International.

Jackendoff, Ray. 2002. Foundations of language: Brain, meaning, grammar, evolution. Oxford: Oxford University Press.

Kiss, Katalin É. 2003. Argument scrambling, operator movement and topic movement in Hungarian. In Simin, Karimi (ed.), Word order and scrambling, 22-43. Malden, MA: Blackwell.

Kiss, Katalin É. 2006. Focusing as predication. In Molnár, Valéria \& Winkler, Susanne (eds.), The architecture of focus. Berlin: Mouton de Gruyter.

Kiss, Katalin É. 2010. Structural focus and exhaustivity. In Zimmermann, Malte \& Féry, Caroline (eds.), Information structure: Theoretical, typological and experimental perspectives, 64-88. Oxford: Oxford University Press.

Koeneman, Olaf. 2000. The flexible nature of verb movement. Utrecht: LOT Publications.

Kosta, Peter \& Franks, Steven L. \& Radeva-Bork, Teodora \& Schurcks, Lilia (eds.). 2014. Minimalism and beyond: Radicalizing the interfaces. Amsterdam: John Benjamins.

Krifka, Manfred. 2007. Basic notions of information structure. In Féry, Caroline \& Fanselow, Gisbert \& Krifka, Manfred (eds.), Working Papers of the SFB632, Interdisciplinary Studies on Information Structure(ISIS) 6. 13-56. Potsdam: Universitätsverlag Potsdam. 
Lechner, Winfried. 2005. Interpretive effects of head-movement. Ms. University of Tübingen (lingBuzz/000178).

Li, Charles N. N. \& Thompson, Sandra. A. 1976. Subject and topic: a new typology of language. In Li, Charles N. N. \& Thompson, Sandra A. (eds.), Subject and topic, 457-461. Austin: University of Texas Press.

Miyagawa, Shigeru. 2003. A-movement scrambling and options without optionality. In Simin, Karimi (ed.), Word order and scrambling, 177-200. Malden, MA: Blackwell.

Mokrosz, Ewelina. 2014. Exhaustive to and infinitives in Polish. Paper presented at 47th Annual Meeting of the Societas Linguistica Europaea. Poznań 2014.

Moro, Andrea. 2008. The Boundaries of Babel. The brain and the enigma of impossible languages. Cambridge, MA: MIT Press.

Murakami, Madoka. 2011. Verb movement: The contrast between English and Polish. Poznań Studies in Contemporary Linguistics $47.569-583$.

Nagaya, Naonori. 2007. Information structure and constituent order in Tagalog. Language and Linguistics 8(1). 343-372.

Paris, Marie-Claude. 1998. Focus operators and types of predication in Mandarin. Cahiers de linguistique - Asie Orientale 27(2). 139-159.

Reinhart, Tanya. 1995. Interface strategies. OTS Working Papers. Utrecht University.

Reinhart, Tanya. 2006. Focus: The PF interface. In Reinhart, Tanya. (ed.), Interface strategies. Reference-set computation, 125-164. Cambridge: MIT Press.

Rizzi, Luigi. 1997. The fine structure of the left periphery. In Haegeman, Liliane (ed.), Elements of grammar, 281-337. Dordrecht: Kluwer.

Rizzi, Luigi. 2004. Locality and left periphery. In Belletti, Adriana (ed.), Structures and beyond: The cartography of syntactic structures, Vol. 3, 223-251. Oxford: Oxford University Press.

Rizzi, Luigi. 2006. On the form of chains: Criterial positions and ECP effects. Cheng, Lisa Lai-Shen \& Corver, Norbert (eds.), Wh movement: Moving on, 97-134. Cambridge, MA: MIT Press.

Roberts, Ian. 2011. Head movement and the Minimalist Program. In Boeckx, Cedric, The Oxford handbook of linguistic Minimalism, 195-219. Oxford: OUP.

Rothstein, Susan. 1983. The syntactic forms of predication. Cambridge, MA: MIT. (Doctoral dissertation.)

Rothstein, Susan. 2006. Predication. In Brown, Keith (ed.), Encyclopedia of language \& linguistics. Second edition, Vol. 10, 73-76. Oxford: Elsevier.

Rutkowski, Paweł. 2006. From demonstratives to copulas: A cross-linguistic perspective and the case of Polish. Journal of Universal Language 7. 147-173.

Saito, Mamoru. 1992. Long distance scrambling in Japanese. Journal of East Asian Linguistics 1. 69-119.

Selkirk, Elizabeth O. 1984. Phonology and syntax. the relation between sound and structure. Cambridge, MA: MIT Press.

Selkirk, Elizabeth O. 1995. Sentence prosody: Intonation, stress, and phrasing. In Goldsmith, John (ed.), The Handbook of phonological theory, 550-569. London: Blackwell.

Surányi, Balázs. 2005. Head movement and reprojection. Annales Universitatis Scientiarum Budapestinensis de Rolando Eötvös Nominatae. Sectio Linguistica. Tomus XXVI. 313-342.

Surányi, Balázs. 2008. Cyclic spell out and reprojection in head movement. In Hartmann, Jutta \& Hegedűs, Veronika \& van Riemsdijk, Henk (eds.), Sounds of silence: Empty elements in syntax and phonology, 293-337. Amsterdam: Elsevier.

Szczegielniak, Adam. 1997. Deficient heads and long head movement in Slovak. Formal Approaches to Slavic Linguistics 5. 312-333.

Tajsner, Przemysław. 2008. Aspects of the grammar of focus: A minimalist view. Frankfurt am Main: Peter Lang.

Tajsner, Przemysław. 2015. On specification and the derivation of copular to-clauses in Polish. Studia Anglica Posnaniensia 50(4). 25-66.

Tajsner, Przemysław \& Cegłowski, Piotr. 2006. Topicalization and object fronting in Polish: A view from a minimalist perspective. In Dziubalska-Kołaczyk, Katarzyna (ed.), IFAtuation: A life in IFA. A Festschrift for professor Jacek Fisiak on the occasion of His 70th birthday, 99-131. Poznań: Wydawnictwo Naukowe UAM.

Wedgwood, Dan. 2003. Predication and information structure. A dynamic account of the Hungarian pre-verbal system. Edinburgh: University of Edinburgh. (Doctoral dissertation.)

Wedgwood, Dan. 2006. Predication, focus, and the positions of negation in Hungarian. Lingua 116. 351-376.

Wiland, Bartosz. 2008. Circumstantial evidence for syntactic head movement. In Abner, Natasha \& Bishop, Jason (eds.), Proceedings of the 27th West Coast Conference on Formal Linguistics, 440-448. Somerville, MA: Cascadilla Proceedings Project. 
Williams, Edwin. 1980. Predication. Linguistic Inquiry 11. 203-238.

Williams, Edwin. 1987. NP trace and theta-theory. Linguistics and Philosophy 10. 203-238.

Witkoś, Jacek. 2007. Polish and the A-type scrambling. In Kosta, Peter \& Schürcks, Lilia. (eds.), Linguistic investigations into formal description of Slavic languages, 165-180. Frankfurt am Main: Peter Lang.

Wolff, H. Ekkehard, \& Löhr, Doris. 2006. Encoding focus in Kanuri verbal morphology: Predication focus and the 'Kanuri focus shift'. ZAS Papers in Linguistics 46. 185-209.

Zubizarreta, Maria Luisa. 1998. Prosody, focus, and word order. Cambridge, MA: MIT Press.

Zubizarreta, Maria Luisa \& Vergnaud, Jean-Roger. 2005. Phrasal stress, focus, and syntax. In Everaert, Martin \& van Riemsdijk, Henk (eds.), The syntax companion. Cambridge: Blackwell. 